\title{
A Rosa Branca: um documento contra a barbárie
}

[The White Rose: a document against the barbarism]

Patrícia da Silva Santos ${ }^{1}$

Inge Scholl. A Rosa Branca. Org.: Juliana P. Perez e Tinka Reichmann. Tradução: Anna Carolina Schäfer e outros. São Paulo: Editora 34, 2013, 272 p.

"Coragem civil" [Zivilcourage] é um conceito muito importante entre os alemães, mesmo em um âmbito cotidiano. Relaciona-se a iniciativas tomadas de acordo com convicções pessoais em oposição a normas, leis ou situações sociais consideradas injustas. Tais iniciativas implicam, portanto, certo grau de coragem. A Rosa Branca, de Inge Scholl, apresenta ao leitor brasileiro um caso histórico exemplar de Zivilcourage, levado a cabo em pleno "estado de exceção" constituído pela Alemanha nazista (conforme a famosa conceituação do jurista Carl Schmitt).

A Rosa Branca foi a designação dada a um pequeno grupo constituído por cinco estudantes e um professor, todos da Universidade de Munique, com o intuito de oferecer resistência passiva ao regime nazista, recorrendo, para tanto, não muito mais do que a uma arma chamada esclarecimento - palavra empregada aqui no sentido básico de elucidar, disseminar informações, prestar subsídios para uma eventual decisão. Assim, seguindo a intenção de esclarecer, os irmãos Hans e Sophie Scholl, seus colegas Christoph Probst, Alexander Schmorell, Willi Graf e o professor de filosofia Kurt Huber redigem e distribuem seis panfletos que denunciam as atrocidades da ditadura nazista; munidos de coragem civil, procuram desconstruir o discurso ideológico

\footnotetext{
${ }^{1}$ Doutoranda do Programa de Pós-graduação em Sociologia da Universidade de São Paulo, bolsista da CAPES, nas modalidades bolsa no país e sanduíche (programa CAPES/DAAD/CNPQ). E-mail: patricia215@gmail.com.
}

Pandaemonium, São Paulo, v. 17, n. 23, Jun. /2014, p. 240-245 


$$
\text { Santos, P. S. - A Rosa Branca - resenha }
$$

nacional-socialista e conclamar os alemães à resistência. Descobertos, todos os integrantes são condenados e mortos pelos tribunais fascistas em 1943.

Inge Scholl, irmã dos integrantes Sophie e Hans Scholl, escreve o livro A Rosa Branca, composto por memórias, transcrições de documentos e relatos de testemunhas. O relato é publicado pela primeira vez na Alemanha em 1952, portanto, ainda sob o forte impacto dos eventos traumáticos vinculados ao nacional-socialismo. Conforme argumenta Rainer HUDEMANN em seu posfácio, os sentimentos imperantes nesse período de pós-guerra concorrem para silenciar a atmosfera pública alemã, então imersa numa "incapacidade de luto" - a recorrência ao conceito freudiano designa, nesse caso, a situação coletiva de "melancolia", ou seja, de incapacidade de assunção, representação e/ou reelaboração dos eventos traumáticos vivenciados (253). O testemunho de Inge Scholl cristaliza-se, nesse contexto, como um material importante para a reflexão sobre os traumas causados pelo fenômeno do nacional-socialismo na sociedade alemã, na medida em que traz ao conhecimento público aquele que, em pouco tempo, seria reconhecido internacionalmente como um dos mais significativos símbolos da resistência alemã à ditadura fascista.

O livro de Inge Scholl é organizado da seguinte forma: além dos prefácios correspondentes à edição brasileira e à alemã, há um relato da autora contendo memórias familiares permeadas por fenômenos sociopolíticos; a obra contém, ainda, a transcrição dos seis panfletos originais; um breve comentário sobre os objetivos da Rosa Branca (anexado a edições posteriores); as sentenças de condenação proferidas pelo fatídico "tribunal do povo" (instância jurídica do estado nazista) contra os membros da Rosa Branca e outros envolvidos; relatos e testemunhos pessoais de pessoas que tiveram participação direta ou indireta nas ações; reações e manifestações de apoio, como o discurso de rádio proferido por Thomas Mann, por exemplo; além disso, o texto contém o rascunho do sétimo panfleto, o discurso de defesa do professor Kurt Huber e o posfácio do historiador Rainer Hudemann (anexado exclusivamente à edição brasileira).

O teor testemunhal dos relatos não é plenamente isento de algumas pequenas imprecisões, sobretudo de ordem cronológica (conforme aponta HUDEMANN: 251), porém, em compensação, ele concede ao leitor a possibilidade de aproximar-se dos eventos narrados de maneira muito intensa, quase visceral, justamente porque narra a partir do cruzamento entre destinos privados concretos e a história. Ou seja, como 


$$
\text { Santos, P. S. - A Rosa Branca - resenha }
$$

"literatura de testemunho" - face da literatura que frutificou intensivamente a partir do século XXI, sobretudo devido à série de catástrofes políticas da época - a recorrência a memórias pessoais para a transmissão narrativa de acontecimentos traumáticos é uma das características de A Rosa Branca.

Destarte, na primeira parte do livro o leitor é informado pela narrativa de Inge Scholl sobre algumas circunstâncias relativas à ascensão e à vigência do estado nacional-socialista alemão: a autora discorre sobre a "juventude hitlerista" e a forma como os jovens alemães foram atingidos por esse movimento; também oferece um panorama de como o discurso antissemita era dosado pela ideologia nazista com ideais da "comunidade do povo" e da pátria mãe; expõe o apelo que as promessas do partido de Hitler exerciam sobre uma sociedade gravemente ferida pelas experiências da última guerra, assim como oferece exemplos de sobriedade por parte daqueles que logo perceberam as falácias de tais promessas; além disso, seu testemunho indica fenômenos pontuais relacionados ao gradativo aumento da censura às liberdades individuais, como a proibição de canções estrangeiras, por exemplo. Um diferencial dessa narrativa é que o relato se materializa, embora não exclusivamente, sob a lupa da esfera familiar dos Scholl: boa parte das informações refere-se à forma como os membros da família vivenciaram as transformações políticas de sua época. Assim, o texto apresenta o ponto de intersecção entre a esfera privada e a esfera do destino coletivo da nação alemã. Precisamente por meio dessa intersecção, ajuda a perceber as diferentes facetas nesta relação entre o âmbito individual e o destino coletivo totalitário.

Uma faceta preponderante de tal relação corresponde, é certo, à falsa "comunidade do povo" que, em muitos casos, paralisou a capacidade humana de discernimento e de ação autônoma diante do fascismo. Nesse sentido, ao lermos o apelo apaixonado dos integrantes de "A rosa branca” e acompanharmos suas trajetórias por meio dos relatos, obtemos uma ideia muito clara da desproporção da luta que essas seis pessoas empreenderam contra o totalitarismo e seu discurso altamente persuasivo, ainda que pautado em ideais irracionais como a "unidade racial".

Por outro lado, o livro de Inge Scholl constitui um documento importante, no sentido de indicar exemplarmente os valores que pautaram um julgamento que se conformou sob o critério da emancipação humana, ainda que sob as condições mais adversas. Assim, embora esse exemplo de resistência de um grupo muito pequeno não 


$$
\text { Santos, P. S. - A Rosa Branca - resenha }
$$

possa simplesmente redimir a barbárie praticada pela coletividade nazista em nome daquela fictícia "comunidade do povo", configura um instrumento para a viabilização da reflexão contínua sobre tais fenômenos.

Nesse sentido, a transcrição dos seis panfletos oferece uma mostra contundente do alto grau de discernimento dos membros da Rosa Branca nos anos de sua atividade (1942/1943), não apenas em relação à contemporaneidade do regime nazista, mas também no que tange ao seu significado num quadro histórico futuro. Com palavras duras, conclamam os alemães a defender o seu "livre-arbítrio", aquilo que "o ser humano possui de mais valioso" e a sair do estado de "rebanho superficial e apático de seguidores alienados" (91). Apontam também o dedo para a "intelectualidade alemã", que teria se refugiado em uma "cova" (95). Mas este apelo dosado com repreensão tem como principal objetivo intensificar aquela arma do esclarecimento citada anteriormente, pois aqueles crimes horrendos que atingiam "profundamente a todos" os alemães deveriam também os "obrigar a refletir" (96). De acordo com o segundo panfleto, cada alemão deveria mesmo "sentir sua parcela de culpa" (97). O terceiro panfleto apresenta alguns exemplos práticos de como a "resistência pacífica" poderia ser exercida por meio de atitudes que levassem ao enfraquecimento do sistema nazista: "sabotagem" às assembleias, às fábricas de armamentos, às publicações nazistas, às coletas de rua etc. (101). O quarto panfleto conclama os concidadãos a não esquecer os nomes dos colaboradores nazistas e, no quinto, o "apelo a todos alemães" aparece reforçado com a seguinte pergunta: "Havemos de ser para sempre o povo odiado e repudiado pelo mundo inteiro?” (107). Contudo, aqui também o intuito é menos imputar "culpa" ao cidadão alemão comum do que conclamá-lo à "luta" pela "livre autodeterminação" (110), pela "capacidade individual de pensar e julgar" (109), conforme expresso no sexto panfleto.

Esses poucos exemplos ilustram a dinâmica paradoxal que perpassa o livro, qual seja: a que circunscreve a fragilidade desse apelo pela liberdade e a força praticamente onipresente do regime totalitário. A relação nazismo-resistência, exposta de maneira cristalina na trajetória do grupo "A rosa branca", expressa bem as contradições intensificadas pela história humana moderna (aquelas que o debate sociofilosófico do século XX conceituou, por exemplo, como servidão versus livre-arbítrio, barbárie versus civilização, mito versus iluminismo). Pontualmente, a constatação desesperada 


$$
\text { Santos, P. S. - A Rosa Branca - resenha }
$$

que inicia o segundo panfleto se refere justamente a essas ambiguidades: "Não é possível enfrentar racionalmente o nacional-socialismo porque ele é irracional. É um equívoco falar de uma visão de mundo nacional-socialista, pois, se esta existisse, seria necessário sustentá-la ou combatê-la com meios racionais" (95). A passagem indica que o nazismo desmobilizou o plano racional que deveria orientar as decisões relativas à assunção de uma visão de mundo determinada. Essa condição cercearia de antemão a possibilidade de contrapô-lo racionalmente. Contudo, ainda assim, a única possibilidade entrevista pela Rosa Branca foi denotar esse ludíbrio constitutivo do nacionalsocialismo. Nesse sentido, o restante do panfleto em questão demonstra que o apelo deseja precisamente contrapor-se à irracionalidade do nazismo e o faz invocando o "discernimento", o pensar "sem descanso". Assim, mesmo percebendo a "fragilidade" da arma esclarecimento - esta que apela para a razão - os membros do grupo não dispunham dos meios que pudessem sustentar a via da força, em uma eventual resistência ativa. Destarte, se o nazismo é um "tumor cancerígeno do povo alemão" (idem), um elemento irracional, porém totalitário, a única coisa que poderia ser feita era tentar demonstrar o lugar histórico indevido que ele ocupava num mundo que já conhecia a ideia (ainda que utópica) do Estado como promotor do "Bem Comum" conforme a conceituação à qual o grupo recorre em um dos panfletos (99). Ou seja, a irracionalidade inerente ao totalitarismo - como o discurso sobre a pureza da raça, todas as mortes nos campos de concentração e na guerra - não deveria sequer constituir uma opção de "visão de mundo".

As “ideias" disseminadas pelos membros da Rosa Branca num ato de extrema coragem civil podem ser agora conferidas pelo leitor brasileiro e contribuir para a manutenção da exigência de que "Auschwitz não se repita", conforme a formulação categórica de Theodor Adorno registrada em Educação após Auschwitz (ADORNO 2006: 119).

Em sua última noite antes de ser decapitada, Sophie Scholl, a única mulher do grupo e também a sua integrante mais jovem, teria tido um sonho, que narrou para a sua companheira de cela. No sonho, antes de cair num precipício que se abriu repentinamente sob seus pés, ela teria tido tempo de colocar de lado, a salvo, a criança que carregava. De acordo com sua interpretação, a criança seria a "ideia" plantada pela resistência empreendida pela Rosa Branca (74). A única coisa que resta a uma sociedade

Pandaemonium, São Paulo, v. 17, n. 23, Jun. /2014, p. 240-245 


$$
\text { Santos, P. S. - A Rosa Branca - resenha }
$$

pós-nazismo para estar à altura do sacrifício de Sophie Scholl e muitos outros (nem sempre nomeados pela história) que, como ela, foram assassinados por lutarem contra "constituições" que impediam "o desenvolvimento das potencialidades humanas" (p. 93), é cuidar desta "criança" e não deixar desvanecer aquelas ideias relativas à "livre autodeterminação" e ao "livre-arbítrio". Nesse sentido, também devido à forma de composição narrativa do livro, uma possibilidade prática oferecida pela tradução de $A$ Rosa Branca é sua introdução para fins educativos no ensino de história ou ética, por exemplo. Na Alemanha, lidar com o tema Rosa Branca é praticamente obrigatório para todos os estudantes.

Autonomia, emancipação, liberdade - estes são conceitos quase onipresentes em qualquer discurso filosófico. E os nomes de filósofos aparecem aqui e ali, tanto no texto de Inge Scholl, como nos outros documentos que compõem o livro. Mas o valor específico de A Rosa Branca não é apenas contribuir conceitualmente para aquelas elaborações iluministas por vezes intangíveis, mas, como testemunho de "fé na liberdade e na honra" (223), consiste em restituir a necessidade de manutenção e reflexão cotidiana sobre a autonomia, a emancipação e a liberdade, mesmo "depois de Auschwitz" e precisamente porque Auschwitz foi possível.

Recebido em: 30/01/2014

aceito em: 08/03/2014 